\title{
EFFECT OF PEA PROTEIN ISOLATE, CARBOXYMETHYL CELLULOSE, PECTIN AND THEIR INTERACTION ON PHYSICOCHEMICAL AND OXIDATIVE STABILITY OF OIL-IN-WATER EMULSIONS
}

\author{
NG PEI QI*, NOR HAYATI IBRAHIM AND AZLIN SHAFRINA HASIM \\ School of Food Science and Technology, Universiti Malaysia Terengganu, 21030 Kuala Nerus, Terengganu, \\ Malaysia
}

${ }^{*}$ Corresponding author: sophieng94@hotmail.com

\begin{abstract}
Biopolymer interaction in oil-in-water (o/w) emulsions has been demonstrated to positively modify the emulsion physicochemical properties which lead to desirable stability. The present work focused on the effect of pea protein isolate (PPI), pectin, carboxymethyl cellulose (CMC) and their interaction on physicochemical properties and oxidative stability of $\mathrm{o} / \mathrm{w}$ emulsions using a mixture design approach. The emulsions were prepared with $40 \%$ sunflower oil stabilized with $1 \%$ of PPI, pectin and $\mathrm{CMC}$, respectively, as well as their mixtures according to a simplex-centroid design (10 points). The $\mathrm{pH}$ values for all emulsions were within acidic condition (3.22 to 4.66) and increased significantly $(\mathrm{p}<0.05)$ as the PPI-CMC level increased. Regression modelling revealed that ternary mixture of PPI-pectin-CMC had the strongest significant $(\mathrm{p}<0.05)$ synergism on 2,2-diphenyl-1picrylhydrazyl (DPPH) scavenging activity $(85.06$ to $91.17 \%)$. Besides, interaction between PPI and CMC significantly $(\mathrm{p}<0.05)$ reduced the interfacial tension and at the same time thickened the interfacial membrane to provide the emulsion with desirable small droplet size $(10.56 \mu \mathrm{m})$. This synergistic interaction effect also significantly $(\mathrm{p}<0.05)$ improved oxidative stability of the emulsion resulting in low total oxidation value $(<7)$ due to decreased oxygen transportation rate across the thick interfacial membrane surrounding the emulsion droplets. Moreover, with high coefficients of determination $\left(\mathrm{R}^{2}>96 \%\right)$ and insignificant lack of fit $(\mathrm{p}>0.05)$ of the fitted models, this study also proved that the mixture design with regression modelling was useful in elucidating PPI, CMC and pectin interactions and also able to empirically predict the responses to any blend of combination of the components.
\end{abstract}

Keywords: Emulsion, pea protein isolate, pectin, carboxymethyl cellulose, mixture design, biopolymer interaction

\section{Introduction}

Oil-in-water (o/w) emulsion such as milk, dressing and mayonnaise is a system in which oil phase is dispersed as fine droplets in an aqueous continuous phase. The system is thermodynamically unstable and thus emulsifiers are needed to stabilize it by decreasing the interfacial tension between oil and water phases, reducing the energy required to break the dispersed phase into droplets, and also preventing them from coalescing (Yang et al., 2016). Recently, there has been increasing interest in exploring the potential of plantbased food emulsifiers. Pea protein isolate (PPI) is one of the most important plant proteins which is extracted from yellow peas. It has been used to prepare emulsions for the production of dry microcapsules (Gharsallaoui et al., 2012) and many studies have been carried out to investigate the emulsifying properties of PPI (Barac et al., 2015; Gharsallaoui et al., 2010; Adebiyi \& Aluko, 2011). Pea protein isolate is able to stabilize $\mathrm{o} / \mathrm{w}$ emulsion due to the surface properties of its constitutive protein units: the storage globulins $7 \mathrm{~S}$ (vicilin) and 11S (legumin) (Gharsallaoui et al., 2010).
Another important biopolymer found in $\mathrm{o} / \mathrm{w}$ emulsion is polysaccharide, a hydrophilic macromolecule used to stabilize the system by viscosity modification or gelation of its continuous phase (Perrechil et al., 2014). Pectin is a complex polysaccharide extracted from the primary cell wall and middle lamella of higher plants, especially citrus peels, apple pomace and sugar beet pulps (Leroux et al., 2003). It has long been identified as a thickening agent by increasing the viscosity of the continuous phase of vegetable oil-based emulsions and mayonnaises (Bouyer et al., 2012). In addition, pectin is believed to have emulsifying property that could effectively form small droplets in emulsions (McClements \& Gumus, 2016). Similar to pectin, carboxymethyl cellulose (CMC) is a water-soluble cellulose derivative which has been widely used in acidified food emulsions to prevent flocculation and this polysaccharide positively interacts with proteins existing in the system such as whey protein isolate (Huan et al., 2016). Besides, CMC is commonly used in food emulsions to prevent gravitational separation of suspended particles (Arancibia et al., 2016). 
Despite suitable characteristics of PPI, pectin and $\mathrm{CMC}$ with regard to their application in o/w emulsions, there are some reported drawbacks that could limit their functionalities in the system. PPI is said to have weak emulsifying properties due to the hydrophobic surface structure, low surface charge and poor solubility as it is easily affected by temperature, $\mathrm{pH}$, ionic strength and solvent type (Gharsallaoui et al., 2010). Meanwhile, emulsion stabilized by polysaccharide alone can induce flocculation due to the formation of bridges as one polymer molecule is adsorbed on 2 or more oil droplets as caused by noncomplexed CMC (Girard et al. 2002). Moreover, Juttulapa et al. (2017) have shown that low concentration of pectin alone is not a good emulsifying agent for stabilizing emulsion due to its low adsorption ability, which is not sufficient to provide effective steric stabilization among oil droplets over a long-term period and against harsh conditions. Furthermore, polysaccharides display lower surface activity than proteins, hence leading to not only larger droplet sizes, but also a much higher polysaccharide concentration required to produce stable emulsions (Li et al., 2012).

Due to limited functionality demonstrated both by protein and polysaccharide when used alone in the $\mathrm{o} / \mathrm{w}$ emulsion, interaction between protein and polysaccharide has been a successful approach for the formulation of highly stable emulsions at broad range of environmental conditions, such as $\mathrm{pH}$, ionic strength and temperature (McClements \& Gumus, 2016). According to Gharsallaoui et al. (2010), emulsion stabilized by PPI with the addition of high methoxyl pectin can improve emulsion stability upon ageing, $\mathrm{pH}$ changes and increase the resistance to depletion flocculation caused by maltodextrin addition. Besides, Huan et al. (2016) reported that emulsion stabilized by the interactions of CMC and whey protein isolate improved surface properties, reduced droplet flocculation and coalescence. Besides, complexation of whey protein isolate and $\mathrm{CMC}$ stabilized emulsion by improving the surface properties of protein and enhancing the repulsion between droplets (Huan et al., 2016). In addition, Tamnak et al. (2016) reported that pectin-PPI conjugated showed lower solubility and higher emulsifying activity than native pectin and PPI alone. However, most studies limited their experimental design on investigating a binary interaction of protein-polysaccharide only.

Mixture design experiment is a special type of response surface experiment which can be used to study the functions of the ingredients in processed foods and approve the importance of ingredient interactions (Karaman et al., 2011). Several studies have been carried out using this approach to elucidate the effects of various ingredients as well as their binary and ternary interaction (synergism/ antagonism) on food emulsions (Nor Hayati et al., 2010; Nor Hayati et al., 2016; Nor Hayati \& Chang, 2017; Karaman et al., 2011). However, to date, no study has been conducted concerning the effect of PPI, pectin and CMC and mixtures. Therefore, this study was undertaken to determine the main and interaction effects of PPI, pectin and CMC on the physicochemical properties and stability of $\mathrm{o} / \mathrm{w}$ emulsions using a mixture design approach.

\section{Materials and Methods Materials}

Pea protein isolate was purchased from LushProtein Pte.Ltd. Pectin from apple pomace and $\mathrm{CMC}$ were purchased from Sigma Aldrich Company. Commercial sunflower oil was purchased from a local supermarket. All chemicals were of analytical grade.

\section{Oil-in-Water Emulsion Preparation}

Pea protein isolate, pectin and CMC dispersion were prepared as described by Nor Hayati et al. (2016) with some modifications. $2.5 \mathrm{~g}$ of PPI, pectin and CMC were separately dissolved in $100 \mathrm{~g}$ of deionized distilled water with vigorous stirring at room temperature $\left(25 \pm 1^{\circ} \mathrm{C}\right)$. The dispersions were stored overnight to ensure complete hydration before mixture preparation. Binary mixtures of PPI:pectin, PPI: $\mathrm{CMC}$ and pectin:CMC were prepared at specific ratios based on an augmented simplex centroid mixture design as depicted in Table 1. All biopolymer mixtures were prepared at $60^{\circ} \mathrm{C}$ with continuous stirring for $30 \mathrm{~min}$. Further, oil-in-water (o/w) emulsion was prepared by using $40 \%$ sunflower oil, $10 \%$ water, $4 \%$ vinegar, $6 \%$ egg yolk and $40 \%$ biopolymer solution. Firstly, a premix of water, vinegar, and egg yolk were homogenized at $10000 \mathrm{rpm}(1 \mathrm{~min})$ using a high speed homogenizer (ULTRA-TURRAX T25 digital, IKA, Germany). Next, sunflower oil and biopolymer mixture were alternately added into the emulsion while homogenization was continued to emulsify the oil for $4 \mathrm{~min}$ at $14000 \mathrm{rpm}$. The homogenization was continued for another $1 \mathrm{~min}$ at 18 $000 \mathrm{rpm}$. Each type of emulsions was prepared in two independent replications for further analyses.

\section{Determination of Physicochemical Properties}

The $\mathrm{pH}$ of o/w emulsions was determined using a $\mathrm{pH}$ meter (Benchtop pH meter, WTW, Germany) equipped with an electrode. The $\mathrm{pH}$ meter was calibrated first with $\mathrm{pH} 10$ and $\mathrm{pH} 4$ buffer, prior to $\mathrm{pH}$ determination of the prepared emulsions. 2,2-diphenyl-1picrylhydrazyl (DPPH) scavenging activity of $\mathrm{o} / \mathrm{w}$ emulsions was determined based on Duan et al. (2016) with some modifications by using UV-vis spectrophotometer (Spectroquant Pharo 300, Merck, EU). $1.0 \mathrm{ml}$ of o/w emulsion sample was added to $2.0 \mathrm{ml}$ of $0.1 \mathrm{mmol} / \mathrm{L}$ DPPH solution dissolved in methanol. The mixture was left to react in dark at room temperature for $30 \mathrm{~min}$. The absorbance was then measured at $517 \mathrm{~nm}$ against a reagent blank. The DPPH radicalscavenging activity was calculated in percentage using the following formula: 
DPPH radical scavenging activity $(\%)=[(1-$

$$
\left.\left.\frac{A_{1}}{A_{o}}\right) \times 100 \%\right]
$$

where, $A_{0}$ is the absorbance of blank and $A_{1}$ is the absorbance of sample.

For droplet size and microstructure observation, droplet image was captured using a light-microscope equipped with eye piece camera (Primo Star, ZEISS, United States). To estimate the droplet size, mean of 20 droplet sizes was calculated by analysing the microscopic images with VMS 3.6 measurement software.

\section{Determination of Oxidative Stability}

All emulsions were allowed to oxidize under room temperature (with incandescent light) for 20 days prior to the following analyses. The peroxide value (PV) was determined according to the AOAC method 965.33 based on titrimetric method (Mei et al. 2014). Subsequently, anisidine value (AV) was determined colorimetrically according to AOCS CD 18-90 (1998) described by Kargar et al. (2011). The final result of oxidative stability was expressed as total oxidation value (TOTOX) determined as: TOTOX value $=\mathrm{AV}+(2 \mathrm{xPV})$

\section{Experimental Design and Statistical Analysis}

Mixture design with an augmented simplex centroid point (10 points) was applied in this study to prepare binary mixtures of PPI: pectin, PPI: CMC and pectin: CMC at ratio $1 \frac{1}{2}: 1 / 2$; ternary mixture of PPI: pectin: CMC at $\operatorname{ratio}_{1 / 3}: 1 / 3: 1 / 3,2 / 3: 1 / 6: 1 / 6 ; 1 / 6: 2 / 3$ : $1 / 6$ and $1 / 6: 1 / 6: 2 / 3$, besides their respective pure counterparts (Table 1). Different proportion of components of $\mathrm{X}_{1}$ (PPI), $\mathrm{X}_{2}$ (pectin), $\mathrm{X}_{3}(\mathrm{CMC})$ between the range of zero and one $\left(0 \leq X_{i} \leq 1 ; \sum X_{i}=1\right)$ were prepared in the experimental domain of this study. The experimental domain was within an equilateral triangle (regular simplex). All treatments were prepared in two replications to result in 20 independent experimental units of emulsion. Detailed description of the design can be found elsewhere (Nor Hayati et al., 2010).
A one-way ANOVA with Tukey's Multiple Comparison was applied on the data to determine any significant differences between emulsions. Data were reported as mean \pm standard deviation with significant letters (if any). The level of confidence used was at $\alpha=$ 0.05 . The relationship between independent variables and dependent variables was analysed using mixture regression analysis to determine estimated coefficients and significance of the model terms, the F-test and coefficient of determinations $\left(\mathrm{R}^{2}\right)$. The model significance, significance of lack-of-fit and adjusted $\mathrm{R}^{2}$ value were used to judge the adequacy of model fitness. Then, the results obtained was fitted into the following generalized mixture regression model:

$$
\begin{array}{r}
Y=\beta_{1} X_{1}+\beta_{2} X_{2}+\beta_{3} X_{3}+\beta_{12} X_{1} X_{2}+\beta_{13} X_{1} X_{3}+ \\
\beta_{23} X_{2} X_{3}+\beta_{123} X_{1} X_{2} X_{3}+\beta_{1123} X_{1}^{2} X_{2} X_{3}+\beta_{1223} X_{1} X_{2}^{2} X_{3}+ \\
\beta_{1233} X_{1} X_{2} X_{3}^{2}(\text { Special Quartic) }
\end{array}
$$

where $Y$ is the predicted analysis response, $\beta_{1}, \beta_{2}$ and $\beta_{3}$ are the estimated coefficient of each linear effect terms, $\beta_{12}, \beta_{13}$ and $\beta_{23}$ are the binary interaction effect terms, $\beta_{1123}, \beta_{1223}, \beta_{1233}$ and $\beta_{123}$ are the ternary interaction effect terms. However, regression analysis revealed that interaction term of $\beta_{1233}$ could not be estimated and was removed from the fitted models. $\mathrm{X}_{1}, \mathrm{X}_{2}$ and $\mathrm{X}_{3}$ are coded value of the independent variables which are PPI, pectin and $\mathrm{CMC}$ concentration respectively.

Table 2 summarizes the results of ANOVA and estimated regression coefficients. The value of adjusted $\mathrm{R}^{2}\left(\mathrm{R}_{\text {adj }}^{2}\right)$ is always lower than the $\mathrm{R}^{2}$, and the closer value of $R^{2}$ adj to $R^{2}$ indicates that non-significant terms were sustained in the models, since it is worth to generally note their effects on the respective responses. The results obtained in this study showed that $\mathrm{R}^{2}$ values for all the response variables were higher than 0.80 , indicating the adequacy of the applied regression model (Joglekar \& May, 1987). Besides, the negative value for the regression coefficient indicated that for every unit increase in the independent variable, the value of the dependent variable decreased and vice versa. In spite of this, synergistic and antagonistic interaction effects elucidated in the following discussion referred solely to desirable and undesirable effects of the blend components on the response variables. All response models also showed insignificant lack of fit $(p>0.05)$ indicating that the models are sufficiently accurate for predicting the response variables. Subsequently, contour and surface plots were generated based on the estimated model equation for each response to visualize the relationship between the response and experimental levels of each factor. All statistical analysis (experimental design, data analysis, contour and surface plots) were carried out by using Minitab 14.0 statistical software. 
EFFECT OF PEA PROTEIN ISOLATE, CARBOXYMETHYL CELLULOSE, PECTIN AND THEIR INTERACTION ON PHYSICOCHEMICAL AND OXIDATIVE STABILITY OF OIL-IN-WATER EMULSIONS

\section{Results and Discussion \\ Effect of Biopolymers and Their Mixtures on Physicochemical Properties}

$\mathrm{pH}$ is an important indicator to determine the shelf-life and stability of emulsion as it will affect the extent of adsorbed protein-polysaccharide interactions. From Table 1, the $\mathrm{pH}$ values of the $\mathrm{o} / \mathrm{w}$ emulsions in this study ranged from 3.22 to 4.66 which were in acidic condition. Formulation C (Pectin) was found to have the lowest $\mathrm{pH}$ value and was significantly different $(\mathrm{p}<0.05)$ from other emulsions whereas Formulation E (CMC) obtained the highest $\mathrm{pH}$ value. Formulation $\mathrm{E}$ was significantly different $(p<0.05)$ from other emulsions except for Formulation F ( $1 \frac{2}{2}$ PPI: $1 / 2$ CMC). In addition, regression analysis demonstrated that binary effect of $1 / 2$ PPI- $1 / 2$ CMC mixture had significant increasing effect $(\mathrm{p}<0.05)$ on the response. Furthermore, contour plot and surface plot in Figure 1 illustrates that $\mathrm{pH}$ of emulsions increased with increasing $\mathrm{CMC}$ proportion while $\mathrm{pH}$ of the emulsion decreased when proportion of pectin increased. This was because the neutral point of CMC is around $\mathrm{pH} 8.25$ (Hakeem et al., 2014) while the $\mathrm{pH}$ range of pectin is around $\mathrm{pH}$ 2.9-3.3 (Whistler \& BeMiller, 1993). The multiple regression equation of $\mathrm{pH}$ is shown in Equation 1 (* Significant coefficient):

$$
\begin{gathered}
\mathrm{pH}=4.41 \mathrm{X}_{1}+3.30 \mathrm{X}_{2}+4.64 \mathrm{X}_{3}-0.10 \mathrm{X}_{1} \mathrm{X}_{2}- \\
\mathbf{0 . 3 4}_{1} \mathbf{X}_{\mathbf{3}} *+0.11 \mathrm{X}_{2} \mathrm{X}_{3}-1.31 \mathrm{X}_{1} \mathrm{X}_{2} \mathrm{X}_{3} \pm 3.06 \mathrm{X}_{1}^{2} \mathrm{X}_{2} \mathrm{X}_{3}+ \\
1.26 \mathrm{X}_{1} \mathrm{X}_{2}^{2} \mathrm{X}_{3}
\end{gathered}
$$

Equation 1

\begin{tabular}{|c|c|c|c|c|}
\hline $\begin{array}{c}\text { Formulation } \\
\text { (PPI:Pectin:CMC) }\end{array}$ & pH & $\begin{array}{c}\text { DPPH } \\
\text { scavenging } \\
\text { activity (\%) }\end{array}$ & $\begin{array}{l}\text { Droplet size } \\
\quad(\mu \mathrm{m})\end{array}$ & Total oxidation \\
\hline $\mathrm{A}(1: 0: 0)$ & $4.40 \pm 0.02^{b}$ & $87.32 \pm 1.03^{\mathrm{ab}}$ & $11.42 \pm 1.08^{\mathrm{bc}}$ & $15.96 \pm 1.18^{\mathrm{a}}$ \\
\hline B $(1 / 2: 1 / 2: 0)$ & $3.83 \pm 0.06^{\mathrm{e}}$ & $85.99 \pm 0.91^{\mathrm{ab}}$ & $19.46 \pm 1.75^{\mathrm{a}}$ & $12.51 \pm 0.11^{\mathrm{bc}}$ \\
\hline $\mathrm{C}(0: 1: 0)$ & $3.30 \pm 0.03^{\mathrm{f}}$ & $76.57 \pm 1.01^{\mathrm{c}}$ & $14.65 \pm 1.39^{\mathrm{b}}$ & $11.55 \pm 0.33^{\mathrm{c}}$ \\
\hline $\mathrm{D}(0: 1 / 2: 1 / 2)$ & $4.00 \pm 0.01^{\mathrm{d}}$ & $75.01 \pm 1.95^{\mathrm{c}}$ & $8.75 \pm 0.79^{\mathrm{cd}}$ & $13.77 \pm 0.23^{b}$ \\
\hline $\mathrm{E}(0: 0: 1)$ & $4.65 \pm 0.02^{\mathrm{a}}$ & $63.93 \pm 1.57^{\mathrm{d}}$ & $5.45 \pm 0.02^{\mathrm{d}}$ & $10.67 \pm 0.42^{\mathrm{c}}$ \\
\hline$F(1 / 2: 0: 1 / 2)$ & $4.61 \pm 0.01^{\mathrm{a}}$ & $73.18 \pm 2.14^{\mathrm{c}}$ & $9.64 \pm 0.71^{\mathrm{c}}$ & $6.35 \pm 0.04^{\mathrm{e}}$ \\
\hline $\mathrm{G}(2 / 3: 1 / 6: 1 / 6)$ & $4.30 \pm 0.05^{b}$ & $87.51 \pm 2.79^{\mathrm{ab}}$ & $10.55 \pm 0.37^{b c}$ & $16.22 \pm 0.01^{\mathrm{a}}$ \\
\hline $\mathrm{H}\left(1 / 6^{2}: 2 / 3: 1 / 6\right)$ & $3.71 \pm 0.01^{\mathrm{e}}$ & $85.90 \pm 0.04^{\mathrm{ab}}$ & $10.86 \pm 0.98^{b c}$ & $8.07 \pm 0.36^{\mathrm{dc}}$ \\
\hline I $(1 / 6: 1 / 6: 2 / 3)$ & $4.41 \pm 0.05^{b}$ & $85.06 \pm 1.15^{\mathrm{b}}$ & $8.68 \pm 0.72^{\mathrm{cd}}$ & $8.81 \pm 0.51 c^{d}$ \\
\hline $\mathrm{J}(1 / 3: 1 / 3: 1 / 3)$ & $4.17 \pm 0.01^{\mathrm{c}}$ & $91.17 \pm 0.46^{\mathrm{a}}$ & $9.64 \pm 0.70^{\mathrm{c}}$ & $11.27 \pm 0.18^{\mathrm{c}}$ \\
\hline
\end{tabular}

Table 1: An augmented simplex centroid mixture design representing different proportions of pea pectin isolate (PPI), pectin and carboxymethyl cellulose (CMC) with responses measured on the respective emulsions.

Data are presented in mean with standard deviation $(n=2) .{ }^{\text {a-f }}$ Means with different superscript in the same column are significantly different $(\mathrm{p}<0.05)$. 
EFFECT OF PEA PROTEIN ISOLATE, CARBOXYMETHYL CELLULOSE, PECTIN AND THEIR INTERACTION ON PHYSICOCHEMICAL AND OXIDATIVE STABILITY OF OIL-IN-WATER EMULSIONS

Table 2: Coefficient of estimation and probability values for each responses generated from regression analysis

\begin{tabular}{lcccc}
\hline \multicolumn{1}{c}{ Terms } & $\mathbf{p H}$ & $\begin{array}{c}\text { DPPH } \\
\text { scavenging } \\
\text { activity (\%) }\end{array}$ & Droplet size $(\boldsymbol{\mu m})$ & $\begin{array}{c}\text { Total } \\
\text { oxidation }\end{array}$ \\
\hline$\beta_{1}$ & 4.4 & 87.5 & 11.4 & 15.9 \\
$\beta_{2}$ & 3.3 & 76.7 & 14.6 & 11.5 \\
$\beta_{3}$ & 4.6 & 64.1 & 5.4 & 10.6 \\
$\beta_{1} \beta_{2}$ & -0.1 & $16.9^{*}$ & $25.5^{*}$ & $-5.1^{*}$ \\
$\beta_{1} \beta_{3}$ & $0.3^{*}$ & -9.1 & $8.3^{*}$ & $-28.0^{*}$ \\
$\beta_{2} \beta_{3}$ & 0.1 & $19.7^{*}$ & -5.4 & $10.5^{*}$ \\
$\beta_{123}$ & -1.3 & $964.2^{*}$ & 112.3 & $-85.5^{*}$ \\
$\beta_{1123}$ & 3.1 & $-972.5^{*}$ & $-273.2^{*}$ & $655.4^{*}$ \\
$\beta_{1223}$ & 1.3 & $-825.5^{*}$ & -416.3 & $-333.9^{*}$ \\
$\mathrm{R}^{2}$ & 99.7 & 97.4 & 96.3 & 98.7 \\
Adjusted $\mathrm{R}^{2}$ & 99.4 & 95.6 & 93.6 & 97.7 \\
Lack of fit & $0.555^{\mathrm{a}}$ & $0.417^{\mathrm{a}}$ & $0.629^{\mathrm{a}}$ & $0.215^{\mathrm{a}}$
\end{tabular}

*Significant $(\mathrm{p}<0.05) ;{ }^{a}$ Not significant $(\mathrm{p}>0.05) ; \beta_{\mathrm{i}}$ : estimated regression coefficient for main linear effect; $\beta_{\mathrm{ij}}$ : estimated regression coefficient for binary interaction effects; $\beta_{\mathrm{ijk}}, \beta_{\mathrm{ijik}}, \beta_{\mathrm{ijjk}}$ : estimated regression coefficient for ternary interaction effects (1: pea protein isolate, PP1; 2: pectin; 3: carboxymethyl cellulose, CMC.

All emulsions in this study were considered stable as they were relatively acidic. According to Yin et al. (2015), acidic condition facilitated the formation of PPI and polysaccharide complex as high speed homogenization disrupted the PPI aggregates and enhanced the electrostatic attraction between PPI and polysaccharide. Besides, polysaccharides extensive interaction was expected to take place at $\mathrm{pH}$ values between the isoelectric point (pI) of the protein and acid dissociation constant, $\mathrm{pKa}$ of the anionic groups on the polysaccharide. The $\mathrm{pl}$ of the PPI is around $\mathrm{pH} 4.5$ (Barac et al., 2010), pKa of the pectin is $\mathrm{pH} 3.5$ (Girard et al., 2002) and the optimum effect of CMC is around
pH 3.8-7.0 (Wustenberg, 2014). In this study, the $\mathrm{pH}$ values were within the range between $\mathrm{pI}$ of the protein and $\mathrm{pKa}$ of the anionic groups on the polysaccharide. Hence, the interactions between PPI, pectin and CMC in emulsion were expected to be taken place and thus resulting in a steric stabilization effect to the system. 

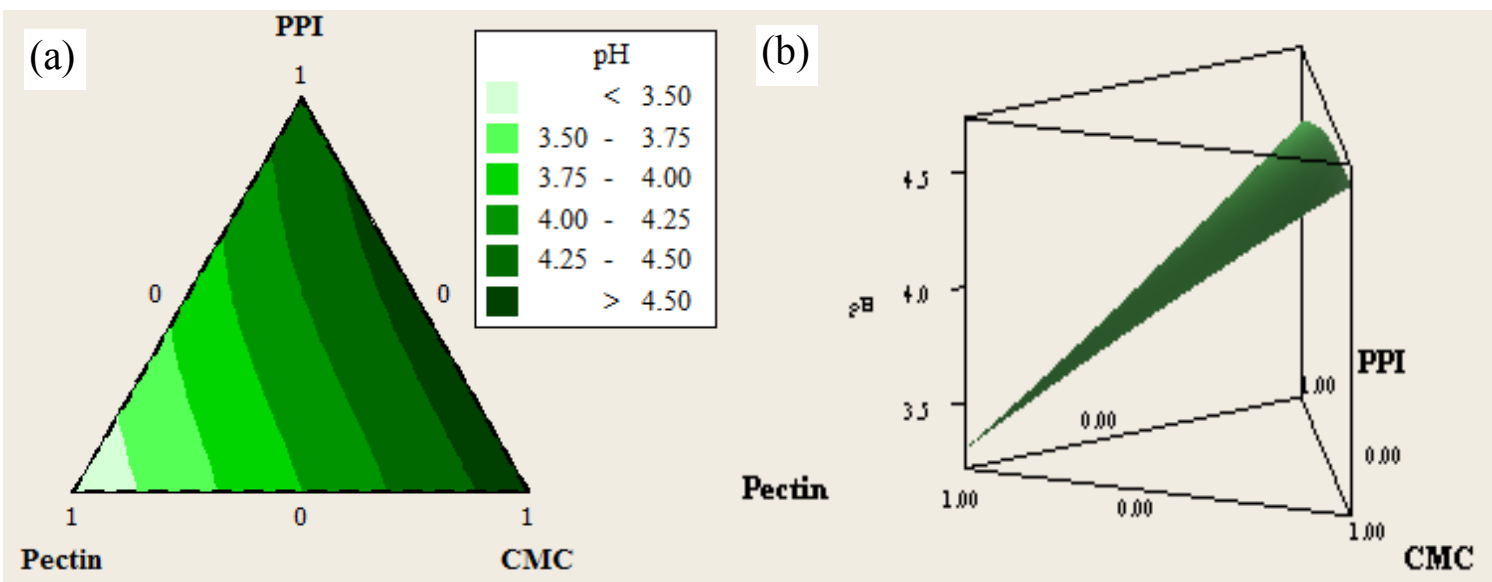

Figure 1: Contour plot (a) and surface plot (b) for $\mathrm{pH}$ of emulsions as a function of pea protein isolate (PPI), pectin, carboxymethyl cellulose (CMC) and their interaction.

In this study, DPPH analysis was used to determine the ability of emulsifiers to act as free radical scavengers or hydrogen donors in the protecting the sunflower oil emulsion from oxidation based on the decrease in the absorbance of a radical-containing solution. The higher the DPPH scavenging activity, the higher the antioxidant activity. As seen in Table 1 , Formulation $\mathrm{J}\left(1 / 3 \mathrm{PPI}:^{1 / 3}\right.$ pectin: $1 / 3 \mathrm{CMC}$ ) indicated the highest DPPH scavenging activity and it was not significantly different from Formulation A (PPI), B ( $1 / 2$ PPI: $1 / 2$ pectin), G $(2 / 3 \mathrm{PPI}: 1 / 6$ pectin: $1 / 6 \quad \mathrm{CMC})$ and $\mathrm{H}(1 / 6$ PPI: $\left.2 / 3^{\text {pectin: }} 1 /{ }_{6} \mathrm{CMC}\right)$. The DPPH scavenging activities for these emulsions were considerably high ranging from $85.90 \%$ to $87.51 \%$. However, Formulation E emulsion which stabilized with CMC showed the lowest DPPH scavenging activity and it was significantly different $(\mathrm{p}<0.05)$ from other emulsions. The most significant factors $(\mathrm{p}<0.05)$ included all interaction terms except PPI-CMC $\left(\mathrm{X}_{1} \mathrm{X}_{3}\right)$, where interaction between PPI-pectin $\left(\mathrm{X}_{1} \mathrm{X}_{2}\right)$ and PPI-pectin$\mathrm{CMC}\left(\mathrm{X}_{1} \mathrm{X}_{2} \mathrm{X}_{3}\right)$ showed synergistic effect implying an increasing effect on the DPPH scavenging activity. However, pectin-CMC $\left(\mathrm{X}_{2} \mathrm{X}_{3}\right)$ and ternary interactions at quadratic level of PPI $\left(\mathrm{X}_{1}^{2} \mathrm{X}_{2} \mathrm{X}_{3}\right)$ and pectin $\left(\mathrm{X}_{1} \mathrm{X}_{2}^{2} \mathrm{X}_{3}\right)$ showed antagonistic effect which decreased the response when the proportion increased. The strongest desirable effect was represented by pure PPI with higher proportion further increased the DPPH scavenging activity followed by pectin emulsifier. Moreover, Figure 2 also illustrates that maximizing effect on DPPH scavenging activity was seen towards the ternary mixture of PPI, pectin and CMC whereas higher CMC proportion contributed to the minimizing effect on the response. The model equation that best described the DPPH scavenging activity in the present study is as follows $(*$ Significant $(\mathrm{p}<0.05)$ coefficient $)$ :

DPPH scavenging activity $=87.5 \mathrm{X}_{1}+76.7 \mathrm{X}_{2}+$ 64.1 $X_{3}+16.9 X_{1} X_{2}^{*}-9.1 X_{1} X_{3}-19.7 X_{2} X_{3} *+964.2$
$X_{1} X_{2} X_{3}^{*}-972.5 X_{1}{ }^{2} X_{2} X_{3}-825.5 X_{1} X_{2}^{2} X_{3}$

Equation 2

The highest synergism of ternary interaction $\left(\mathrm{X}_{1} \mathrm{X}_{2} \mathrm{X}_{3}\right)$ was observed on the antioxidant scavenging activity in emulsion. This is because PPI contains sulfurcontaining groups that acts as hydrogen donor and electron donor to the free radical (Pownall et al., 2010). Similar finding also reported by Pownall et al. (2011), where peptides fraction in the PPI structure possesses a good electron-donating ability and is capable of inhibiting linoleic acid oxidation and chelated metals. Besides their thickening effect on the emulsion continuous phase, pectin and CMC were able to increase the thickness of the interfacial layer and immobilize prooxidative ions which may add to the antioxidative effect of the PPI (Tamm et al., 2016). Therefore, combining the antioxidant ability of the PPI, pectin and CMC resulted in the strongest synergistic effect that increased hydroxyl radical scavenging activity and reduced power. In contrast, pectin-CMC $\left(\mathrm{X}_{2} \mathrm{X}_{3}\right)$ showed antagonistic effect on DPPH scavenging activity in emulsion because CMC does not contain free hydroxyl groups that can interact with DPPH free radicals. Furthermore, the weak antioxidant activity of $\mathrm{CMC}$ may be due to their insoluble form at low $\mathrm{pH}$ values $(<6.0)$ where $\mathrm{CMC}$ carries net opposite charges (Ibrahim et al., 2011). 

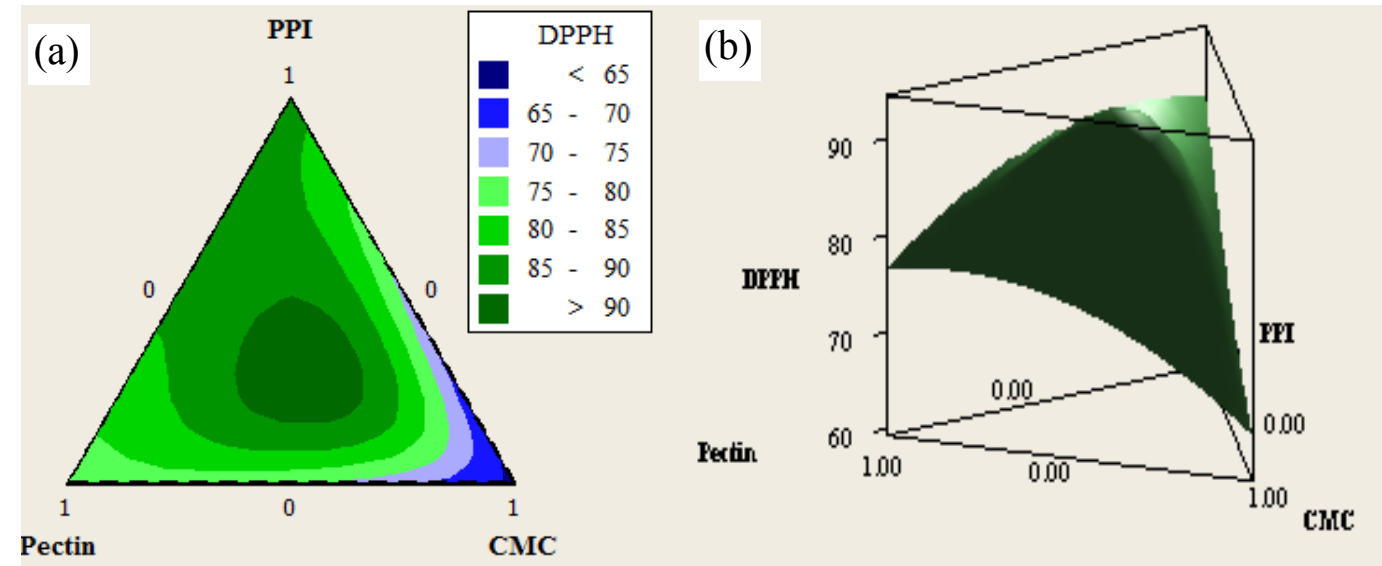

Figure 2: Contour plot (a) and surface plot (b) for DPPH scavenging activity of emulsions as a function of pea protein isolate (PPI), pectin, carboxymethyl cellulose (CMC) and their interaction.

On the other hand, pectin was found to possess lower antioxidant activity than PPI (lower coefficient magnitude than PPI shown in Equation 2) but the presence of hydroxyl groups in pectin's structure enabled it to act as hydrogen and electron donor (Ro et al., 2013). Therefore, the interaction between pectin and $\mathrm{CMC}$ emulsifier insufficiently stabilized the emulsion against the free radicals. The result is also supported by the contour and surface plots in Figure 2 whereby the lowest DPPH scavenging activity minimized towards area with increasing proportion of pectin and CMC.

For droplet microstructure, all emulsions seemed to be pronouncedly different from each other due to their difference in the biopolymer proportion of their mixture counterparts as shown in Figure 3. Formulation B (1/2 PPI: $1 / 2$ pectin) (Figure 3a) and Formulation E (CMC) (Figure 3b) reflected their distintive droplet microstructure. As supported by the droplet size data (Table 1) Formulation B demonstrated the largest droplet size and it was significantly different $(p<0.05)$ from other emulsions whereas the droplet size of Formulation $E$ recorded the smallest size. However, there was no significant difference among Formulation D ( $1 / 2$ pectin: $1 / 2$
CMC ) and I (1/6 PPI: $1 / 6$ pectin: $2 / 3$ CMC) (Table 1$)$. Table 2 shows that the PPI-pectin $\left(\mathrm{X}_{1} \mathrm{X}_{2}\right)$ and PPI-CMC $\left(\mathrm{X}_{1} \mathrm{X}_{3}\right)$ possessed positive coefficient and exhibited antagonism effect where they were significantly increased $(p<0.05)$ on the droplet size of the emulsion. However, there was no significant increasing effect of linear $\left(\mathrm{X}_{1}, \mathrm{X}_{2}, \mathrm{X}_{3}\right)$ and ternary interaction $\left(\mathrm{X}_{1} \mathrm{X}_{2} \mathrm{X}_{3}\right)$ on the response. Interestingly, ternary interactions at quadratic level ( $\sim 67 \%$ of the biopolymer mixture) of PPI $\left(\mathrm{X}_{1}^{2} \mathrm{X}_{2} \mathrm{X}_{3}\right)$ showed substantial and significant decrease in the droplet size with very large magnitude of coefficients (Equation 3). The results indicated that its emulsifying capacity becomes important at such high level. The model fitted for droplet size response is as follows $(*$ Significant $(\mathrm{p}<0.05)$ coefficient $)$ :

$$
\begin{gathered}
\text { Droplet size }=11.4 X_{1}+14.6 X_{2}+5.4 X_{3}+\mathbf{2 5 . 5} \mathbf{X}_{\mathbf{1}} \mathbf{X}_{\mathbf{2}} * \\
+\mathbf{8 . 3} \mathbf{X}_{\mathbf{1}} \mathbf{X}_{\mathbf{3}} *-5.4 X_{2} X_{3}+112.3 X_{1} X_{2} X_{3}- \\
\mathbf{3 7 3 . 2}_{\mathbf{1}^{2} \mathbf{X}_{\mathbf{2}} \mathbf{X}_{\mathbf{3}}-416.3 X_{1} X_{2}^{2} X_{3}}
\end{gathered}
$$

Equation 3

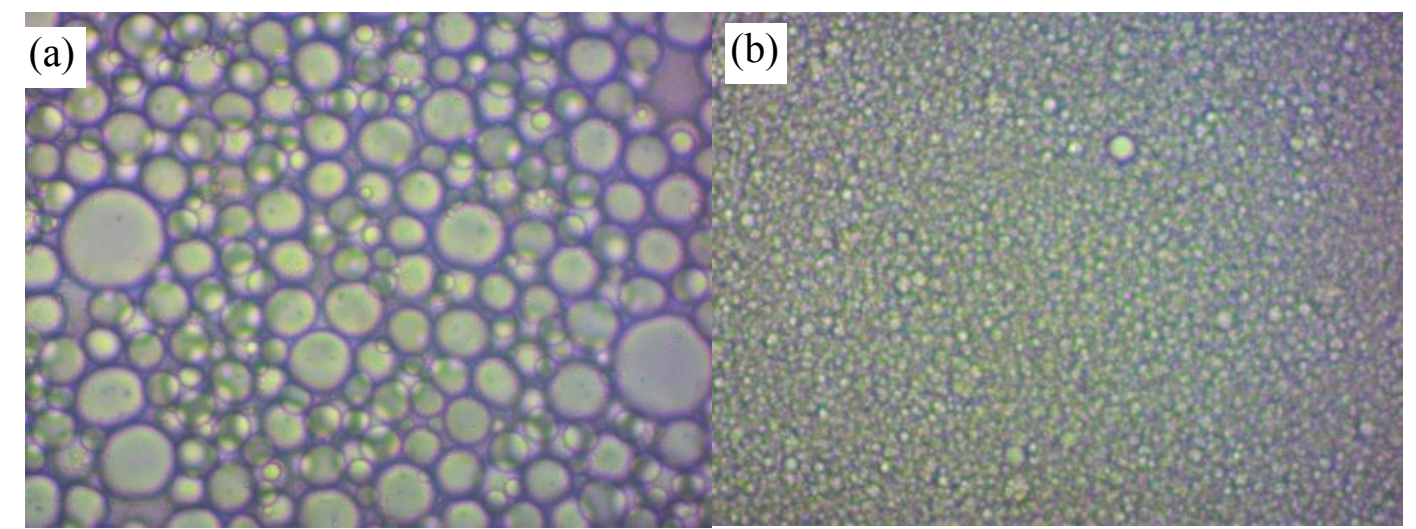

Figure 3: Representative droplet microstructure of Formulation B ( $1 / 2$ PPI:1/2 pectin) (a) and Formulation E (CMC) (b) under 40X magnification. 
Figure 4 also illustrates that as the proportion of $\mathrm{CMC}$ increased, the droplet size of emulsion became smaller compared to PPI and pectin stabilized emulsions. Similar result can also be seen in Equation 3, where coefficient of CMC $\left(\mathrm{X}_{3}\right)$ showed smaller value than PPI $\left(\mathrm{X}_{1}\right)$ and pectin $\left(\mathrm{X}_{2}\right)$. The result is supported by Huan et al. (2016), where the addition of CMC even at $0.04 \%$ significantly reduced the droplet size due to the overall increase negative charges on the surface of the droplets. The finding was also in agreement with a study done by Arancibia et al. (2016) which reported that increased CMC concentration decreased the average droplet size of emulsion and increased viscosity of the aqueous phase. Furthermore, for the linear effect, pectin $\left(\mathrm{X}_{2}\right)$ showed the highest effect on increasing droplet size of emulsion than PPI $\left(\mathrm{X}_{1}\right)$ and CMC $\left(\mathrm{X}_{3}\right)$ emulsifier. This observation was in agreement with a previous study by Mirhosseini et al. (2010) who pointed out that the average droplet size of oil-in-pectin emulsion solution increased when the pectin concentration was increased. This observation may be due to the relationship between the average droplet size and the viscosity of continuous phase (Kawakatsu et al., 2001). In their study, they described that the increase in pectin content contributed to the increase in the viscosity of continuous phase

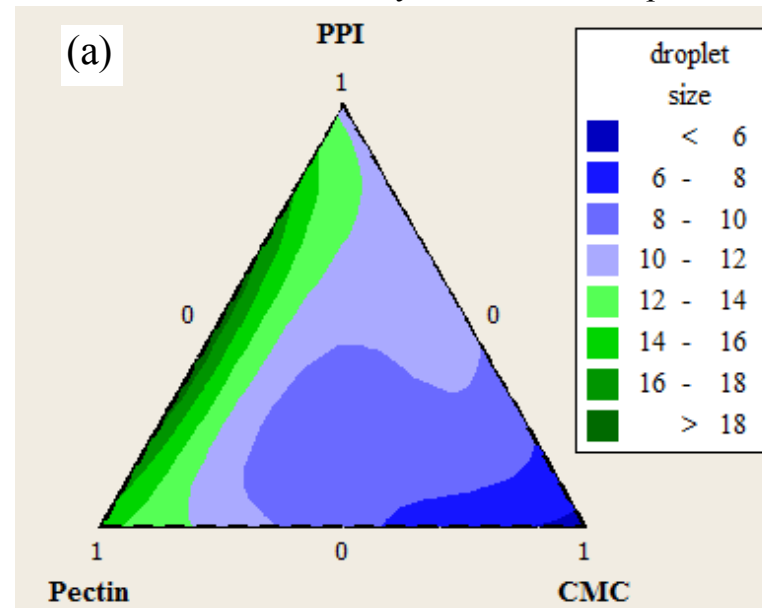

followed by the increase in average droplet size due to a delay in droplet release from the microchannel and the increase in the dispersed phase supply during the formation of each droplet. On the other hand, relatively large-sized droplets also found in PPI emulsion were due to the droplets flocculation at $\mathrm{pH} 4.30-4.43$ which was close to pI of PPI. Therefore, the droplet charge is relatively low and has less electrostatic repulsion to prevent aggregation (Demetriades et al., 1997).

This study also revealed that synergism among PPI, pectin and $\mathrm{CMC}\left(\mathrm{X}_{1}^{2} \mathrm{X}_{2} \mathrm{X}_{3}\right)$ at higher level of PPI in the biopolymer mixture pronouncedly decreased the droplet size in relative to the effect of PPI $\left(\mathrm{X}_{1}\right)$ alone, with a large negative coefficient depicted in Equation 3. This result was in agreement with the study of Huan et al. (2016) that showed that at high level protein concentration, there was better complexation of proteinpolysaccharide and consequently, the droplets were effectively stabilized by both electrostatic and steric interactions. Similar finding was also obtained in other studies that showed that anionic polysaccharides can reduce the aggregation of protein-stabilized emulsion droplets at $\mathrm{pH}$ near $\mathrm{pI}$ of the proteins (Liu et al., 2012).

(b)

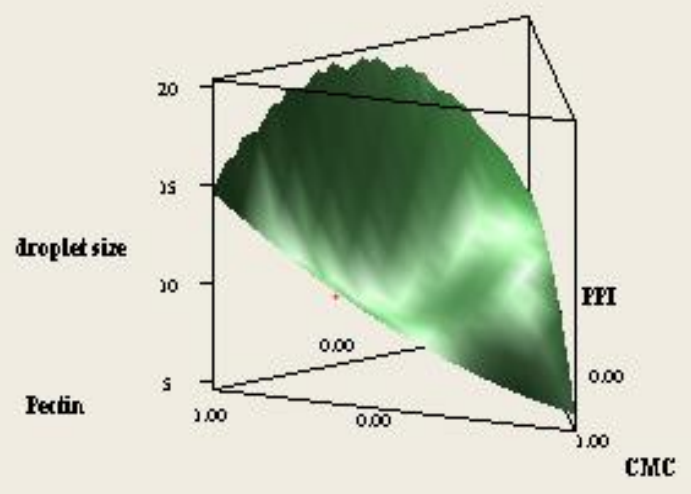

Figure 4: Contour plot (a) and surface plot (b) for droplet size of emulsions as a function of pea protein isolate (PPI), pectin, carboxymethyl cellulose (CMC) and their interaction.

\section{Effect of Biopolymers and Their Mixtures on Oxidative Stability}

Total oxidation value is an evaluation of both primary and secondary oxidative products used to estimate the extent of lipid oxidation and thus more meaningful to be tested on oxidized emulsions rather than the freshly prepared emulsions. As displayed in Table 1, Formulation G (2/3 PPI: $1 / 6$ pectin: $1 / 6 \mathrm{CMC}$ ) showed the highest TOTOX value and it was not significantly different $(\mathrm{p}>0.05)$ from Formulation A (PPI). As can be seen from Figure 5, the binary interaction between PPI and CMC showed lower TOTOX value for both fresh and stored emulsions compared to linear effect and other binary interaction effects. This indicated the occurrence of synergistic effect between PPI and CMC in reducing the lipid oxidation. The oxidation inhibitory effect of PPI was attributed to the solvent-accessible amino acids residues which had strong radicalscavenging activity while $\mathrm{CMC}$ increased the viscosity of continuous phase of emulsion and formed a thicker interfacial membrane on the surface of the droplet which delayed the diffusion of oxidative initiators into the oil droplets. Therefore, synergistic effect of PPI-CMC displayed stronger suppressions of oxidation than with PPI and CMC alone (Zhang et al., 2014). Moreover, PPI alone showed the lowest oxidative stability as it has lower surface charge and easy susceptible to aggregation and flocculation (Yin et al., 2015). 


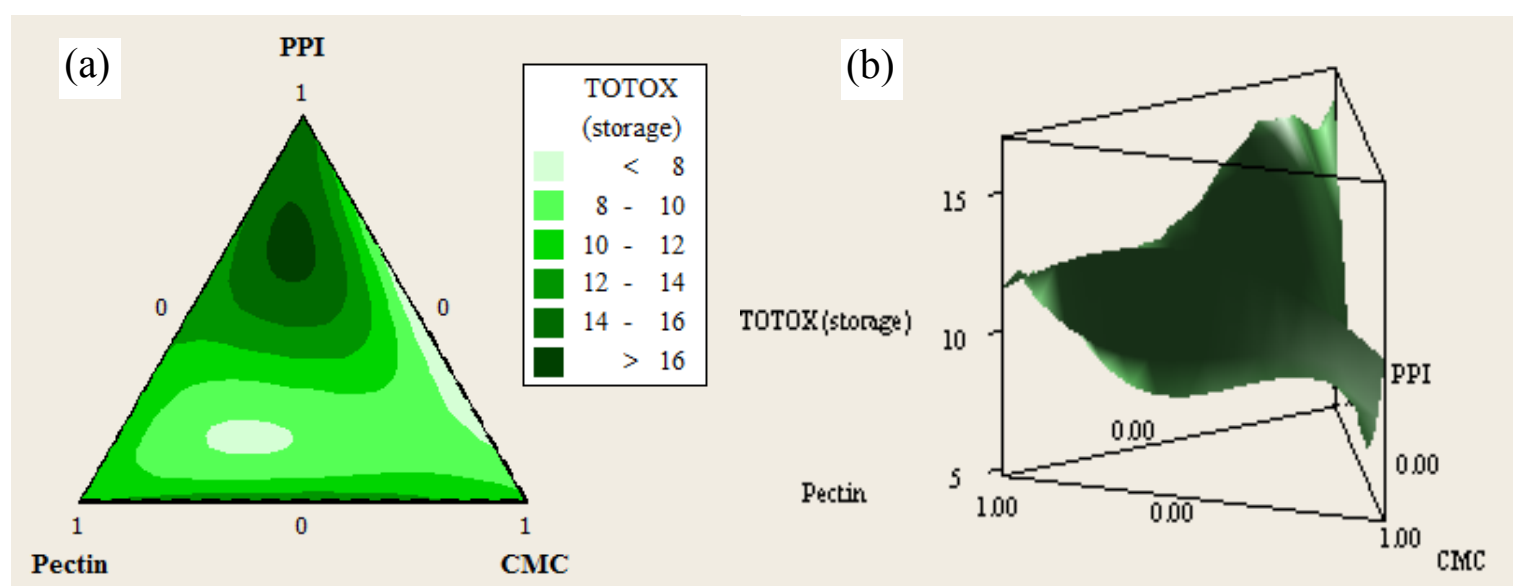

Figure 5: Contour plot (a) and surface plot (b) for TOTOX value of emulsion as a function of pea protein isolate (PPI), pectin, carboxymethyl cellulose (CMC) and their interaction.

As displayed in Table 2, binary interaction and the ternary interaction between PPI, pectin and CMC showed the most decreasing effect in the TOTOX value as indicated by the respective negative coefficients of estimation. According to Owens et al. (2017), interaction between protein and polysaccharide could increase the viscosity of continuous phase and further increase the oxidative stability of emulsion. Similar finding was also obtained in Nguyen et al. (2011) which found that the mixture of emulsifiers could provide a positive effect on the prevention of lipid oxidation as it improved gravity aqueous stability through droplet size reduction and controlled oxidation stability of the emulsion system. Furthermore, the addition of more pectin in the mixture could decrease lipid oxidation rates as it reduced the $\mathrm{pH}$ of the emulsion (as discussed before) through the electrical repulsion of metal ions away from the positive surface charge of the emulsion droplets, thereby reducing contact between prooxidants and the oxidation substrate (Hu et al., 2003). This fact was evidenced with the largest negative coefficient of $\mathrm{X}_{1} \mathrm{X}_{2}^{2} \mathrm{X}_{3}$ interaction term in the following Equation 4 (* Significant $(\mathrm{p}<0.05)$ coefficient):

$$
\begin{aligned}
& \text { TOTOX value }(\text { stored })=15.9 \mathrm{X}_{1}+11.5 \mathrm{X}_{2}+10.6 \mathrm{X}_{3} \text {. } \\
& \text { 5.1 }_{1} X_{2} *-28.0 X_{1} X_{3} *+10.5 X_{2} X_{3} *-85.5 X_{1} X_{2} X_{3} *+ \\
& 655.4 \mathrm{X}_{1}^{2} \mathrm{X}_{2} \mathrm{X}_{3}^{*} \text { - 333.9 } \mathrm{X}_{1} \mathrm{X}_{2}^{2} \mathrm{X}_{3} \text { * }
\end{aligned}
$$

\section{Conclusion}

Equation 4

The present study focused on the main and interaction effects of PPI, pectin and CMC on physicochemical properties and stability of $\mathrm{o} / \mathrm{w}$ emulsions by using a mixture design approach. Most of the results showed that binary effect of PPI, pectin and CMC significantly improved the responses measured on the prepared emulsions compared to their respective linear effects. The responses were also believed to be enhanced with synergistic interaction effect between $\mathrm{CMC}$ and pectin. The $\mathrm{pH}$ value of emulsions increased when the CMC level increased whereas the $\mathrm{pH}$ of emulsion decreased when the pectin level increased. The ternary synergistic effect of PPI-pectin-CMC mixture was the most significant factor that positively affected DPPH scavenging activity of the emulsion. Furthermore, the emulsion droplet size was improved significantly when more PPI interacted with pectin-CMC as the interaction was able to reduce the interfacial tension and stabilize the protein-stabilized emulsion droplets at $\mathrm{pH}$ near isoelectric point ( $\mathrm{pI}$ ) of the protein. In terms of oxidative stability, binary synergism between PPI-pectin, PPI$\mathrm{CMC}$ and pectin-CMC mixtures significantly improved the emulsion oxidative stability as evaluated based on their TOTOX value. This synergism was believed to be related with formation of thicker interfacial membrane and steric barrier effect that decreased the oxygen transport rate. In addition, the study also proved that the mixture design with regression modelling was useful in elucidating PPI, CMC and pectin interaction and in empirically predicting the responses to any blend of combination of the components.

\section{Acknowledgements}

The authors acknowledge the financial and instrumental supports provided by UMT for this project.

\section{References}

Adebiyi, A. P., \&, Aluko, R. E. (2011). Functional properties of protein fractions obtained from commercial yellow field pea (Pisum sativum L.) seed protein isolate. Food Chemistry, 128, 902-908.

Arancibia, C., Navarro-Lisboa, R., Zuniga, R., \& Matiacevich, S. (2016). Application of CMC as thickener on nanoemulsions based on olive oil: Physical properties and stability. International Journal of Polymer Science, 51, 1-11.

Barac, M., Cabrilo, S., Pesic, M., Stanojevic, S., Zilic, S., Macej, O., \& Ristic, N. (2010). Profile and functionalpProperties of seed proteins from six pea 
EFFECT OF PEA PROTEIN ISOLATE, CARBOXYMETHYL CELLULOSE, PECTIN AND THEIR INTERACTION ON PHYSICOCHEMICAL AND OXIDATIVE STABILITY OF OIL-IN-WATER EMULSIONS

(Pisum sativum) genotypes. International Journal of Molecular Science, 11, 4973-4990.

Barac, M. B., Pesic, M. B., Stanojevic, S. P., Kostic, A. Z., \& Bivolarevic, V. (2015). Comparative study of the functional properties of three legume seed isolates: adzuki, pea and soy bean.International of Food Science and Technology, 52(2), 2779-2787.

Bouyer, E., Mekhloufi, G., Rosilio, V., Grossiord, J. L., \& Agnely, F. (2012). Proteins, polysaccharides, and their complexes used as stabilizers for emulsions: Alternatives to synthetic surfactants in the pharmaceutical field? International Journal of Pharmaceutics, 436(1-2), 359-378.

Demetriades, K., Coupland, J. N., \& McClements, D. J. (1997). Physical properties of whey protein stabilized emulsions as related to $\mathrm{pH}$ and $\mathrm{NaCl}$. Journal of Food Science, 62(2), 342-347.

Duan, X., Li, M., Ma, H., Xu, X., Jin, Z., \& Liu, X. (2016). Physicochemical properties and antioxidant potential of phosvitin-resveratrol complexes in emulsion system. Food Chemistry, 206, 102-109.

Gharsallaoui, A., Saurel, R., Chambin, O., \& Voilley, A. (2012). Pea (Pisum sativum, L.) protein isolate stabilized emulsions: A Novel system for microencapsulation of lipophilic ingredients by spray drying. Food and Bioprocess Technology, 5(6), 2211-2221.

Gharsallaoui, A., Yamauchi, K., Chambin, O., Cases, E., \& Saurel, R. (2010). Effect of high methoxyl pectin on pea protein in aqueous solution and at oil/water interface. Carbohydrate Polymers, 80(3), 817-827.

Girard, M., Turgeon, S., \& Paquin, P. (2002). Emulsifying properties of whey proteincarboxymethylcellulose. Journal of Food Science, 67(1), 113-119.

Hakeem, K. R., Jawaid, M., \& Rashid, U. (2014). Biomass and bioenergy. Springer International Publishing, New York.

Hu, M., McClement, D. J., \& Decker, E. A. (2003). Impact of whey protein emulsifiers on the oxidative stability. Journal of Agriculture and Food Chemistry, 51, 1435-1439.

Huan, Y., Zhang, S., \& Vardhanabhuti, B. (2016). Influence of the molecular weight of carboxymethyl cellulose on properties and stability of whey proteinstabilized oil-in-water emulsions. Journal of Dairy Science, 99(5), 3305-3315.

Ibrahim, F. O., Hassan, I., Abdelrashid, A., \& Manal, M. R. (2011). Effect of clouding agents on the quality of apple juice during storage. Food Hydrocolloids, 25, 91-97.
Joglekar, A. M., \& May, A. T. (1987). Product excellence through design of experiments. Cereal Foods World, 32, 857-868.

Juttulapa, M., Piriyaprasarth, S., \& Sriamornsak, P. (2017). Effect of $\mathrm{pH}$ on stability of oil-in-water emulsions stabilized by pectin-zein complexes. Advanced Materials Research, 747, 127-130.

Karaman, S., Yilmaz, M. T., \& Kayacier, A. (2011). Simplex lattice mixture design approach on the rheological behavior of glucomannan based salephoney drink mixtures: An optimization study based on the sensory properties. Food Hydrocolloids, 25(5), 1319-1326.

Kargar, M., Spyropoulos. F., \& Norton, I. T. (2011). Microstructural design to reduce lipid oxidation in oil-in-water emulsion. Procedia Food Science, 1, 104-108.

Kawakatsu, T., Tragardh, G., \& Tragardh, C. (2001). The formation of oil droplets in a pectin solution and the viscosity of the oil-in-pectin solution emulsion. Journal of Food Engineering, 50,247-254.

Leroux, J., Langendorff, V., Schick, G., Vaishnav, V., \& Mazoyer, J. (2003). Emulsion stabilizing properties of pectin. Food Hydrocolloids, 17, 55-462.

Li, J. L., Cheng, Y. Q., Wang, P., Zhao, W. T., Yin, L. J., \& Saito, M. (2012). A novel improvement in whey protein isolate emulsion stability: Generation of an enzymatically cross-linked beet pectin layer using horseradish peroxidase. Food Hydrocolloids, 26(2), 448-455.

Liu, L., Zhao, Q., Liu, T., Kong, J., Long, Z., \& Zhao, M. (2012). Sodium caseinate/carboxymethylcellulose interactions at oilwater interface: Relationship to emulsion stability. Food Chemistry, 132, 1822-1829.

McClements, D. J., \& Gumus, C. E. (2016). Natural emulsifiers - biosurfactants, phospholipids, biopolymers, and colloidal particles: Molecular and physicochemical basis of functional performance. Advances in Colloid and Interface Science, 234, 326.

Mei, W. S., Ismail, A., Esa, N. M., Akowuah, G. A., Wai, H. C., \& Seng, Y. H. (2014). The effectiveness of rambutan (Nephelium lappaceum L.) extract in stabilization of sunflower oil under accelerated conditions. Antioxidants (Basel), 3(2), 371-386.

Mirhosseini, H., Tan, C. P., \& Naghshineh, M. (2010). Influence of pectin and CMC content on physicochemical properties of orange. Journal of Food, Agriculture and Environment 8(2), 134-139.

Nguyen, H. H., Choi, K. O., Kim, D. E., Kang, W. S., \& Ko, S. (2011). Improvement of oxidative stability of 
rice bran oil emulsion by controlling droplet size. Journal of Food Processing and Preservation, 17, 113.

Nor Hayati, I., \& Chang, H. W. (2017). Physical properties of dressing-type oil in water emulsions as affected by okra gum-xanthan gum-corn starch interactions. Malaysian Applied Biology, 46(1), 131137.

Nor Hayati, I., Che Man, Y. B., Tan, C. P., \& Idris, N. A. (2010). Mixture design experiment on flow behaviour of $\mathrm{O} / \mathrm{W}$ emulsions as affected by polysaccharide interactions. World of Academy of Science, Engineering and Technology, 67, 10001006.

Nor Hayati, I., Wai Ching, C., \& Rozaini, M. Z. H. (2016). Flow properties of o/w emulsions as affected by xanthan gum, guar gum and carboxymethyl cellulose interactions studied by a mixture regression modelling. Food Hydrocolloids, 53, 199-208.

Owens, C., Griffin, K., Khouryieh, H., \& Williams, K. (2017). Creaming and oxidative stability of fish oilin-water emulsions stabilized by whey proteinxanthan-locust bean complexes: Impact of pH. Food Chemistry, 239, 314-322.

Perrechil, F. A., Santana, R. C., Lima, D. B., Polastro, M. Z., \& Cunhai, R. (2014). Emulsifying properties of maillard conjugates produced from sodium caseinate and locust bean gum. Brazilian Journal of Chemical Engineering, 31, 429-438.

Pownall, T. L., Udenigwe, C. C., \& Aluko, R. E. (2010). Amino acid composition and antioxidant properties of pea seed (Pisum sativum L.) enzymatic protein hydrolysate fractions. Journal of Agricultural and Food Chemistry, 58, 4712-4718.

Pownall, T. L., Udenigwe, C. C., \& Aluko, R. E. (2011). Effects of cationic property on the in vitro antioxidant activities of pea protein hydrolysate fractions. Food Research International, 44, 10691074.
Ro, J., Kim, Y., Kim, H., Jang, S. B., Lee, H. J., Chakma, S., \& Lee, J. (2013). Anti-oxidative activity of pectin and its stabilizing effect on retinyl palmitate. The Korean Journal of Physiology and Pharmacology, 17(3), 197-201.

Tamm, F., Härter, C., Brodkorb, A., \& Drusch, S. (2016). Functional and antioxidant properties of whey protein hydrolysate/pectin complexes in emulsions and spray-dried microcapsules, LWT Food Science and Technology, 6, 53-57.

Tamnak, S., Mirhosseini, H., Tan, C. P., Ghazali, H. M., \& Muhammad, K. (2016). Physicochemical properties, rheological behavior and morphology of pectin-pea protein isolate mixtures and conjugates in aqueous system and oil-in-water emulsion. Food Hydrocolloids, 56, 405-416.

Whistler, R. L., \& BeMiller, J. N. (1993). Industrial gum polysaccharides and their derivative. Academic Press, Inc. United Kingdom.

Wustenberg, T. (2014). Cellulose and cellulose derivatives in the food industry: Fundamentals and applications. Wiley-VCH, New York.

Yin, B., Zhang, R., \& Yao, P. (2015). Influence of pea protein aggregates on the structure and stability of pea protein/soybean polysaccharide complex emulsions. Molecules, 20, 5165-5183.

Yang, N., Mao, P., Zhang, K., Fang, Y., Nishinari, K., \& Phillips, G. O. (2016). Stability and oil migration of oil-in-water emulsions emulsified by phaseseparating biopolymer mixtures. Journal of Food Science, 2, 1-10.

Zhang, X., Xiong, Y. L., Chen, J., \& Zhou, L. (2014). Synergy of licorice extract and pea Protein hydrolysate for oxidative stability of soybean oil-inwater emulsions. Journal of Agriculture and Food Chemistry, 62, 8204-8213. 